\title{
Image size in the fundus: structural evidence for wide-field retinal magnification factor
}

\author{
A L HOLDEN AND F W FITZKE \\ From the Department of Visual Science, Institute of Ophthalmology, Judd Street, London WC1H 9QS
}

SUMmARY A simple geometrical method is described of calculating the retinal magnification factor (micrometres/degree) at the ora serrata of the human eye. At the ora the magnification factor is some $176 \mu \mathrm{m} / \mathrm{deg}$., whereas at the posterior pole it is $276 \mu \mathrm{m} / \mathrm{deg}$. This result may be of clinical use in examinations where dimensions of tears and holes near the ora serrata are estimated.

The projection of the visual field on the retina is central to many ophthalmological investigations, including perimetry and funduscopy. There has been continued interest in this mapping and its scale variations. It is often important in clinical investigations to examine the periphery of the retina ${ }^{12}$ as well as the posterior pole of the eye, and to appreciate that the scale relating degrees in the visual field to distance on the retina differs between these two locations.

In this note we calculate the scale of the projection of the visual field on the retina at the far periphery of the human eye. Scale is conventionally expressed as a magnification factor (distance on the retina per degree of visual angle, usually stated as $\mu \mathrm{m} /$ degree). Fig. 1 illustrates how this scale can be envisaged. Two pairs of rays are drawn, and each pair subtends an angle $\theta$ degrees at the pupil plane. At the retina the rays are separated by a distance $\mathrm{x}$ micrometres at the posterior pole and $y$ micrometres more peripherally. The magnification factor is the distance divided by the angle $\theta$.

The retinal magnification factor at the posterior pole has been estimated to be some $260-300 \mu \mathrm{m} /$ degree, based on Gaussian schematic eye calculation ${ }^{3}$ and on estimation of the distance from fovea to optic disc derived from retinal histology and perimetry. It has been shown by calculation using wide-field schematic eyes ${ }^{4-6}$ that the retinal magnification factor declines from the posterior pole to the periphery.

Fig. 2, derived from the wide-field eye of Fitzke, ${ }^{6}$ shows how the retinal magnification factor declines across the visual field, from some $270 \mu \mathrm{m} /$ degree at the optic axis to $150 \mu \mathrm{m} /$ degree at the far periphery. There is surprisingly little experimental evidence for Correspondence to Dr A L Holden. such a decline in magnification factor with eccentricity. Frisen and Scholdstrom ${ }^{7}$ marked a human retina with laser lesions, then verified their spacing after enucleation, but measurements were not possible at eccentricities greater than $50^{\circ}$ (the region of the visual field where the decline is greatest).

We wish to state a simple empirical argument, based on ocular structure, which allows a reasonably accurate estimate of the peripheral retinal magnification factor in man. The argument hinges on the projection of the peripheral visual field on the ora serrata. The topography of the ora serrata has been carefully described by Straatsma and colleagues. ${ }^{8}$ The average diameter of the ora serrata, based on 200 eyes, is $20.22 \mathrm{~mm}$ (SD 1.065 mm): we have averaged their vertical and horizontal readings, which differ by less than $2 \%$.

Let us assume that the visual field of the eye can be described by co-ordinates within a hemisphere, with the optical axis directed at a pole. Angles of eccentricity are measured as the angle subtended between a point and the optic axis. In such a spherical coordinate system another angle is required to specify location within the visual field: this meridional angle is measured as a rotation around the optical axis.

Let us assume that the most peripheral ring of retina views visual space at an eccentricity of $90^{\circ}$ (this assumption is discussed further below). DuboisPoulsen ${ }^{9}$ measured in 10 cadaver eyes that the retina views to at least $85^{\circ}$ of eccentricity. A ring of retina viewing visual space at an eccentricity of $90^{\circ}$ views the base of the visual hemisphere, which subtends $360^{\circ}$ of meridional visual angle. Retinal magnification factor (MF) measured circumferentially around the ora serrata and circumferentially in the visual field can be expressed as: $\mathrm{MF}=$ circumference of ora/arc length 


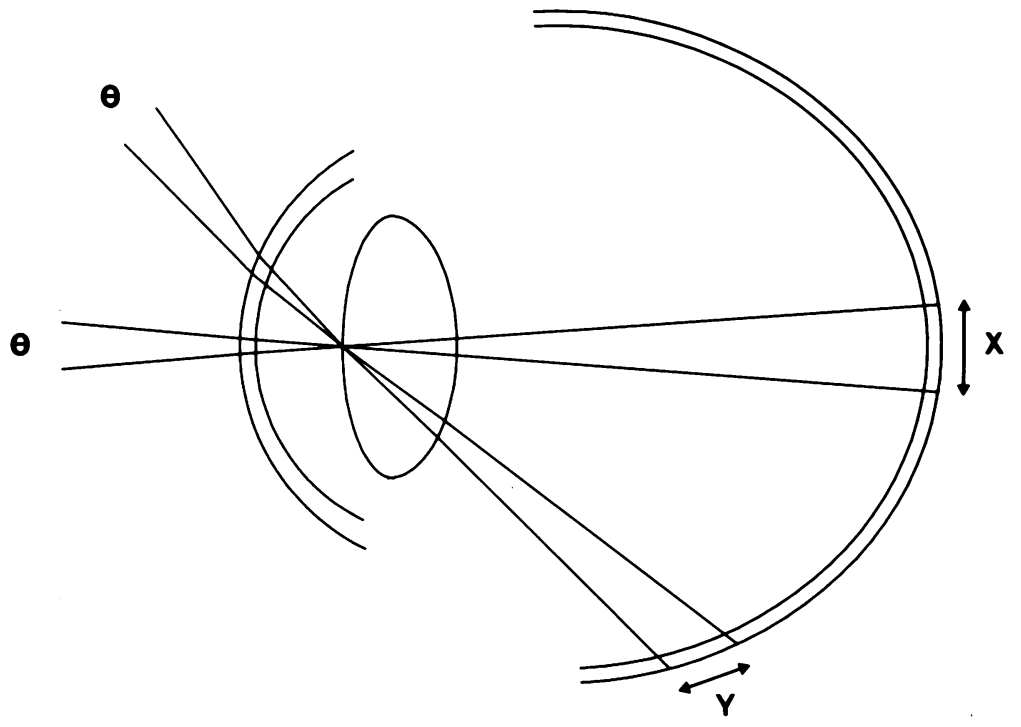

Fig. 1 Magnification factor at the posterior pole and retinal periphery. At the posterior pole a pair of rays separated by the angle $\theta$ projects on $x$ micrometres of retina. At the periphery a pair of rays also separated by the angle $\theta$ projects on $y$ micrometres of retina. The rays have been traced through the optical surfaces by wide-field ray tracing. All rays pass through the centre of the anterior surface of the lens, which corresponds approximately to the pupil centre for a small pupil.

(or angle subtended), which, from the data of Straatsma et al. ${ }^{8}$ is $63 \cdot 5 / 360$, equal to $176 \mu \mathrm{m} /$ degree. This value is plausibly close to the magnification factor calculated from wide-field eyes. ${ }^{56}$

Our value is based directly on anatomical measurement, with an explicit assumption of visual field geometry. We do not take into account the somewhat ovoid shape of the ora; if this were done, magnification factor could be estimated from the true arc length in the visual field.

However, since this arc length is proportional to the sine of the angle of eccentricity, its value changes slowly as eccentricity passes through $90^{\circ}$ : if the base of the hemisphere is given an arc length of 1 , then a

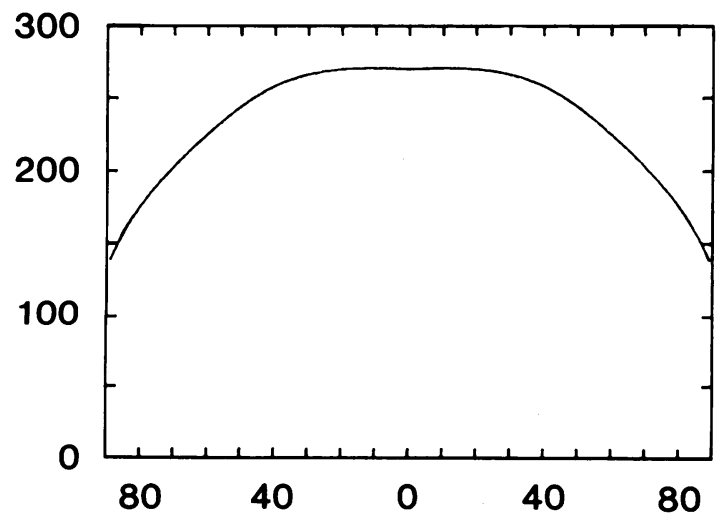

Fig. 2 Variation of retinal magnification factor with eccentricity, based on the computed wide-field eye of Fitzke. ${ }^{6}$ Abscissa: degrees from optic axis. Ordinate: retinal magnification factor, $\mu \mathrm{m} /$ degree. $10^{\circ}$ change in eccentricity results in an arc length of 0.985 , and a $20^{\circ}$ change results in an arc length of 0.94 . Hence, even if the limits of the retinal field are somewhat displaced from an eccentricity of $90^{\circ}$, the estimated peripheral magnification factor will be little affected.

The data of Straatsma et al. ${ }^{8}$ can be used to provide a standard deviation of retinal magnification factor in the far periphery of some $9 \mu \mathrm{m} /$ degree, and hence $95 \%$ confidence limits of $\pm 18 \mu \mathrm{m} /$ degree (158 to 195 $\mu \mathrm{m} /$ degree).

The scale we have derived, of $176 \mu \mathrm{m} /$ degree, is an average figure. It may, however, be of supplementary help in clinical examination where holes, tears, and other features are observed close to the ora serrata. Where features are charted 'round the clock' in meridional angle the distance separating them, or their size, can be readily calculated. The principle of our calculation can be applied to animal eyes, where ora dimensions and the extent of the optical and retinal field can be readily measured.

\section{References}

1 Schepens CL. Progress in detachment surgery. Trans Am Acad Ophthalmol 1951; 55: 607-15.

2 Karlin DB, Curtin BJ. Peripheral chorioretinal lesions and axial length of the myopic eye. Am J Ophthalmol 1976; 81: 625-35.

3 Southall JPC. Helmholtz's treatise on physiological optics. Optical Society of America: George Banta Publishing Company, 1924: 1.

4 Stine GH. Tables for accurate retinal localisation. Am J Ophthalmol 1934; 17: 314-24.

5 Drasdo N, Fowler CW. Non-linear projection of the retinal image in a wide-angle schematic eye. BrJ Ophthalmol 1974; 58: 709-14.

6 Fitzke FW. A representational schematic eye. In: Hughes A, ed. Modelling the eye with gradient index optics. London: Cambridge University Press, in press. 
7 Frisen L, Scholdstrom G. Relationship between perimetric eccentricity and retinal locus in a human eye. Acta Ophthalmol (Kbh) 1977; 55: 63-8.

8 Straatsma BR, Landers MB, Kreiger AE, Apt L. Topography of the adult human retina. In: Straatsma BR, Allen RA, Hall MO,
Crescitelli F, eds. The retina. Berkley: University of California Press, 1969: 379-410.

9 Dubois-Poulsen A. Le champ visuel. Paris: Masson, 1952.

Accepted for publication 27 January 1987. 